\title{
Steroids from the Whole Plants of Leucaena Leucocephala
}

\author{
Chung-Yi Chen*, Yau-Der Wang \\ School of Medical and Heath Science, Fooyin University, Kaohuing, Taiwan, China \\ E-mail:xx377@mail.fy.edu.tw \\ Received January 10, 2009; revised February 21, 2009; accepted February 23, 2009
}

\begin{abstract}

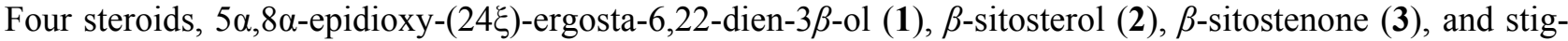
mastenone (4), along with 10 known compounds were isolated from the whole plants of Leucaena leucocephala (Leguminosae). 1, Lupeol (5), 1,3-dipalmitoyl-2-oleoylglycerol (6), methylparabene (8) and isovanillic acid (9) were found for the first time from the species. The structure of these compounds were characterized and identified by spectra analyses.
\end{abstract}

Keywords: Steroids, Leucaena Leucocephala, Leguminosae

\section{Introduction}

Leucaena leucocephala (Leguminosae) is a small, leguminous and native to tropical America, now widely distributed in southern Asia and neighboring islands [1]. Previous studies have show that gallocatechin, epigallocatechin, catechin and epicatechin, extracted from the roots of $L$. leucocephala was found to exhibit the nitrification inhibition bioassay against the bacterium Nitrosomonas europaea [2]. L. leucocephala was chosen for further phytochemical investigation. The $\mathrm{MeOH}$ extract of its plants were subjected to solvent partitioning and chromatographic separation to afford 14 pure substances. The chemical constituents in the plants of L. leucocephala were separated with column chromatography.

Investigation on the $\mathrm{MeOH}$ extract of the plants has led to the isolation of 14 compounds, four steroids: $5 \alpha$,

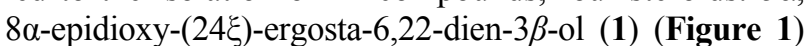
[3], $\beta$-sitosterol (2) (Figure 2) [4], $\beta$-sitostenone (3) (Figure 3) and stigmastenone (4) (Figure 4) [5]; one terpenoid: lupeol (5) [6]; one glyceride: 1,3-dipalmitoyl2-oleoylglycerol (6) [7]; one alkanoid: linoleic acid (7) [8]; two benzenoids: methylparabene (8) [9] and isovanillic acid (9) [10]; and five chlorophylls: pheophytin-a (10) [11], pheophorbide a methyl ester (11) [12], methyl-13 $3^{2}$ - hydroxy-(132 $\left.-S\right)$-pheophorbide-b (12) [13], $13^{2}$-hydroxy-(132-S)-pheophytin-a (13) [14] and aristophyll-C (14) [15]. These compounds were obtained and characterized by the comparison of their physical and spectral data (UV, IR, NMR and MS) with values obtained in the literature. Among them, 1, 5, 6, 8 and 9 were found for the first time from the species.

The specimen of $L$. leucocephala was collected from Pingtung County, Taiwan in December, 2008. A voucher specimen was characterized by Dr. Jin-Cherng Huang of Department of Forest Products Science and Furniture Engineering, National Chiayi University, Chiayi, Taiwan and deposited in the School of Medical and Health Sciences, Fooyin University, Kaohsiung County, Taiwan. The air-dried seeds of $L$. leucocephala $(5.0 \mathrm{~kg})$ were extracted with $\mathrm{MeOH}(80 \mathrm{~L} \times 6)$ at room temperature and the $\mathrm{MeOH}$ extract $(162.5 \mathrm{~g})$ was obtained upon concentration under reduced pressure. The $\mathrm{MeOH}$ extract was chromatographed over silica gel (800 g, 70-230 mesh) using $n$-hexane/acetone as eluent to produce 5 fractions. Part of fraction $1(6.11 \mathrm{~g})$ was subjected to Si gel chromatography by eluting with $n$-hexane/acetone (40:1),

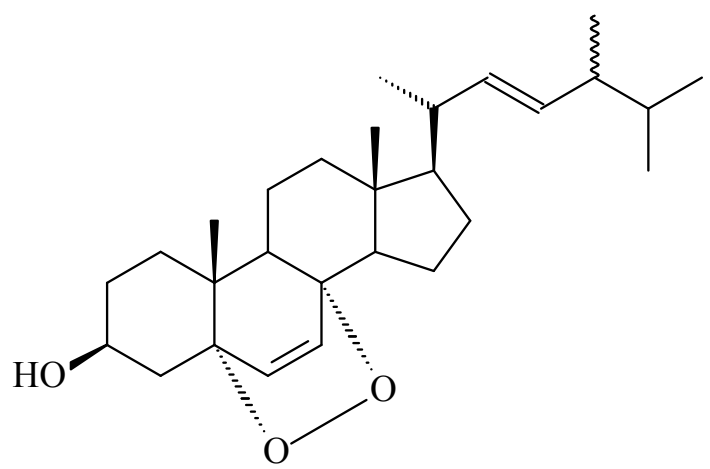

Figure 1. Chemical structure of $5 \alpha, 8 \alpha$-epidioxy-(24 $\xi)$-ergosta6,22-dien-3-ol (1). 
<smiles>CC[C@H](CC[C@@H](C)[C@H]1CCC2C3CC=C4CC(O)CC[C@]4(C)C3CC[C@]21C)C(C)C</smiles>

Figure 2. Chemical structure of $\beta$-sitosterol (2).<smiles>CC[C@H](CC[C@@H](C)[C@H]1CCC2C3CCC4=CC(=O)CC[C@]4(C)C3CC[C@]21C)C(C)C</smiles>

Figure 3. Chemical structure of $\beta$-sitostenone (3).<smiles>CC[C@H](/C=C/[C@H](C)[C@H]1CCC2C3CCC4=CC(=O)CC[C@]4(C)C3CC[C@]21C)C(C)C</smiles>

Figure 4. Chemical structure of stigmastenone (4).

enriched with acetone to furnish 10 fractions (1-1 to 1-10). Fraction 1-1 (1.72 g) was re-subjected to $\mathrm{Si}$ gel chromatography, eluting with $n$-hexane/acetone $(80: 1)$ to obtain linoleic acid (7) (58 mg, 0.0357\%). Part of fraction $3(6.94 \mathrm{~g})$ was subjected to $\mathrm{Si}$ gel chromatography by eluting with $n$-hexane/acetone $(50: 1)$ to obtain $\beta$-sitosterol (2) (15 mg, 0.0092\%). Part of fraction 4 $(6.77 \mathrm{~g})$ was subjected to $\mathrm{Si}$ gel chromatography by eluting with $n$-hexane/acetone $(8: 1)$, then enriched with acetone to furnish 7 fractions (4-1 to 4-7). Fraction 4-5 $(0.62 \mathrm{~g})$ was further purified by another silica gel column using $n$-hexane/acetone to obtain methylparabene (8)
(8 mg, 0.0049\%) and isovanillic acid (9) (12 mg, 0.0074\%).

The air-dried brown beans of L. leucocephala $(5.0 \mathrm{~kg})$ were extracted with $\mathrm{MeOH}(80 \mathrm{~L} \times 6)$ at room temperature and the $\mathrm{MeOH}$ extract (171.5 g) was obtained upon concentration under reduced pressure. The $\mathrm{MeOH}$ extract was chromatographed over silica gel using $n$-hexane/ acetone as eluent to produce 6 fractions. Part of fraction 1 (7.02 g) was subjected to Si gel chromatography by eluting with $n$-hexane/acetone $(40: 1)$ to obtain $\beta$-sitostenone (3) (6 mg, 0.0035\%) and stigmastenone (4) (4 mg, 0.0023\%). Part of fraction 2 (8.49 g) was subjected to Si gel chromatography by eluting with $n$-hexane/ acetone (10:1), then enriched with acetone to furnish 8 fractions (2-1 to 2-8). Fraction 2-3 (2.33 g) was re-subjected to Si gel chromatography, eluting with $n$-hexane/ acetone (40:1) to obtain lupeol (5) (74 mg, 0.0431\%). Part of fraction 3 (7.76 g) was subjected to Si gel chromatography by eluting with $n$-hexane/acetone (40:1) to obtain 1, 3-dipalmitoyl-2-oleoylglycerol (6) (9 mg, $0.0052 \%)$. Part of fraction $6(13.89 \mathrm{~g})$ was subjected to Si gel chromatography by eluting with $n$-hexane/acetone (4:1), then enriched with acetone to obtain $5 \alpha, 8 \alpha$-epidioxy( $24 \xi$ )-ergosta-6,22-dien-3 $\beta$-ol (1) (43 mg, 0.0251\%).

The air-dried leaves of L. leucocephala $(5.0 \mathrm{~kg})$ were extracted with $\mathrm{MeOH}(80 \mathrm{~L} \times 6)$ at room temperature and the $\mathrm{MeOH}$ extract (159.5 g) was obtained upon concentration under reduced pressure. The $\mathrm{MeOH}$ extract was chromatographed over silica gel using $n$-hexane/ acetone as eluent to produce 7 fractions. Part of fraction 1 (6.62 g) was subjected to Si gel chromatography by eluting with $n$-hexane/acetone $(50: 1)$ to obtain pheophytin-a (10) (6 mg, 0.0038\%). Part of fraction 3 (7.56 g) was subjected to Si gel chromatography by eluting with $n$-hexane/acetone $(8: 1)$, then enriched with acetone to furnish 12 fractions (3-1 to 3-12). Fractions 3-7 (2.97 g) was re-subjected to $\mathrm{Si}$ gel chromatography, eluting with $n$-hexane/acetone $(40: 1)$ to obtain $13^{2}$-hydroxy- $\left(13^{2}-S\right)$ pheophytin-a (13) (12 mg, 0.0075\%) and methyl-132hydroxy-(132 $-S)$-pheophorbide-b (12) (9 mg, 0.0056\%). Part of fraction 6 (17.15 g) was subjected to Si gel chromatography by eluting with $n$-hexane/acetone $(4: 1)$ to obtain aristophyll-C (14) (4 mg, 0.0025\%).

The air-dried green beans of L. leucocephala $(5.0 \mathrm{~kg})$ were extracted with $\mathrm{MeOH}(80 \mathrm{~L} \times 6)$ at room temperature and the $\mathrm{MeOH}$ extract (146.5 g) was obtained upon concentration under reduced pressure. The $\mathrm{MeOH}$ extract was chromatographed over silica gel using $n$-hexane/ acetone as eluent to produce 8 fractions. Part of fraction 4 (7.19 g) was subjected to $\mathrm{Si}$ gel chromatography by eluting with $n$-hexane/acetone (8:1) to obtain pheophorbide a methyl ester (11) (8 mg, 0.0055\%).

\section{Acknowledgements}

This investigation was supported by a grant from the 
National Science Council of Republic of China (NSC 97-2320-B-242-002-MY3).

\section{References}

[1] A. M. Gamal-Eldeen, H. Amer, W. A. Helmy, R. M. Talaat and H. Ragab, "Chemically-Modified Polysaccharide Extract Derived from Leucaena leucocephala Alters Raw 264.7 Murine Macrophage Functions," International Immunopharmacology, Vol. 7, No. 6, March 2007, pp. 871-878.

[2] A. J. Erickson, R. S. Ramsewak, A. J. Smucker and M. G. Nair, "Nitrification Inhibitors from the Roots of Leucaena leucocephala," Journal of Agricultural and Food Chemistry, Vol. 48, No. 12, December 2000, pp. 61746177.

[3] A. Gauvin, J. Smadja, M. Aknin, R. Faure and E. Gaydou, "Isolation of Bioactive $5 \alpha, 8 \alpha$-Epidioxy-Sterols from the Marine Sponge Luffarie-lla cf. variabilis," Canadian Journal of Chemistry, Vol. 78, July 2000, pp. 986-992.

[4] L. Chen and W. Kang, "Chemical Constituents from Aeschynanthus longicaullis," China Journal of Chinese Materia Medica, Vol. 34, No. 21, November 2009, pp. 2758-2760.

[5] C. Y. Jiang, S. Z. Mu, B. Deng, Y. H. Ge, J. X. Zhang and X. J. Hao, "Studies on the Chemical Constituents from Euphorbia chrysocoma," Journal of Chinese Medicinal Materials, Vol. 32, No. 9, September 2009, pp. 1390-1392.

[6] C. Zhao, J. Shao and X. Li, "Chemical Constituents from Fruits of Ailanthus altissima," China Journal of Chinese Materia Medica, Vol. 34, No. 17, September 2009, pp. 2197-2199.

[7] T. Arishima, K. Sugimoto, R. Kiwata, H. Mori and K. Sato, ${ }^{~}{ }^{13} \mathrm{C}$ Cross-Polarization and Magic-Angle Spinning Nuclear Magnetic Resonance of Polymorphic Forms of Three Triacylglycerols," Journal of the American Oil
Chemists' Society, Vol. 73, No. 10, May 1996, pp. 1231-1236.

[8] I. L. Tsai, Y. F. Jeng, B. Jayaprakasam and I. S. Chen, "Cytotoxic Constituents from the Leaves of Litsea akoensis," The Chinese Pharmaceutical Journal, Vol. 53, No. 6, December 2001, pp. 291-301.

[9] H. K. Wang and K. H. Lee, "Plant-Derived Anticancer Agents and their Analogs Currently in Clinical Use or in Clinical Trials," Botanical Bulletin of Academia Sinica, Vol. 38, No. 2, March 1997, pp. 225-235.

[10] X. H. Yang, H. B. Lee, H. Chen, P. Li and B. P. Ye, "Chemical Constituents in the Leave of Rhizophora stylosa L and their Biological Activities," Acta Pharmaceutica Sinica, Vol. 43, No. 9, September 2008, pp. 974-978.

[11] W. T. Li, H. W. Tsao, Y. Y. Chen, S. W. Cheng and Y. C. Hsu, "A Study on the Photodynamic Properties of Chlorophyll Derivatives Using Human Hepatocellular Carcinoma Cells," Phytochemical and Phytobiological Sciences, Vol. 6, No. 12, December 2007, pp. 1341-1348.

[12] M. C. Rho, M. Y. Chung, H. Y. Song, O. E. Kwon, S. W. Lee, J. A. Baek, K. H. Jeune, K. Kim, H. S. Lee and Y. K. Kim, "Pheophorbide A-Methyl Ester, Acyl-CoA: Cholesterol Acyltransferase Inhibitor from Diospyros kaki," Archives of Pharmacal Research, Vol. 26, No. 9, September 2003, pp. 716-718.

[13] M. S. Buchanane, T. Hashimoto and Y. Asakawa, "Phytyl Esters and Phaeophytins from the Hornwort Megaceros flagellaris," Phytochemistry, Vol. 41, No. 5, March 1996, pp. 1373-1376.

[14] L. Ma and D. J. Dolphin, "Stereoselective Synthesis of New Chlorophyll $a$ Related Antioxidants Isolated from Marine Organisms," Journal of Organic Chemistry, Vol. 61, No. 7, April 1996, pp. 2501-2510.

[15] Y. Y. Chan, Y. L. Leu and T. S. Wu, "The Constituents of the Leaves of Aristolochia heterophylla Hemsl.," Chemical and Pharmaceutical Bulletin, Vol. 47, No. 6, June 1999, pp. 887-889. 